Supporting Information

\title{
A Superior Potassium-Ion Anode Material from Pitch-based Activated Carbon Fibers with Hierarchical Pore Structure Prepared by Metal Catalytic Activation
}

Wenjie Wei ${ }^{a}$, Fei Wang a , Jianxiao Yang a ${ }^{*}$, Jialing Zou ${ }^{\text {a }}$, Jun Li ${ }^{b}$, Kui Shi ${ }^{{ }^{*}}$

\begin{abstract}
${ }^{a}$ Hunan Province Key Laboratory for Advanced Carbon Materials and Applied Technology, College of Materials Science and Engineering, Hunan University, Changsha, 410082, CHINA.

${ }^{\mathrm{b}}$ School of Chemistry and Food Engineering, Changsha University of Science and Technology, Changsha, 410114, CHINA.
\end{abstract}

\section{*Corresponding authors.}

TEL: +86-731-8882-2733; FAX: +86-731-8882-2733

E-mail address: yangjianxiao@hnu.edu.cn (J. Yang)

E-mail address: shikui@hnu.edu.cn (S. Kui) 

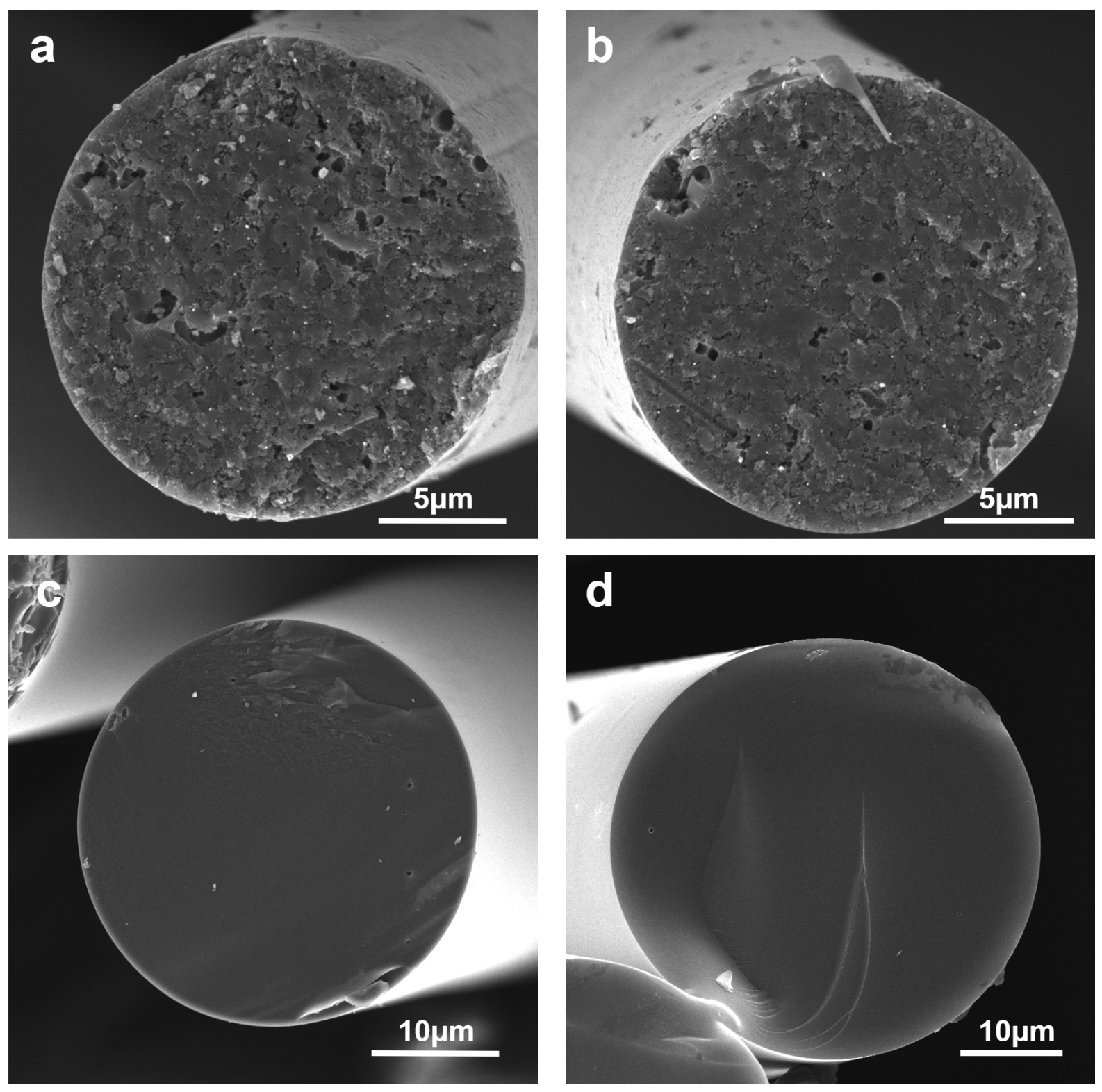

Figure S1. SEM images of (a) ACF/NiS, (b) ACF/NiO, (c) ACF, (d) CF/NiO.

The cross-sectional views of $\mathrm{ACF} / \mathrm{NiO}$ and $\mathrm{ACF} / \mathrm{NiS}$ indicated that there are many pores inside the fiber, and the metal nanoparticles are evenly distributed inside (Figure S1a, $\mathrm{S} 1 b$ ). And, there was no obvious pores in cross-sectional views of $\mathrm{ACF}$ and $\mathrm{CF} / \mathrm{NiO}$ (Figure S1c, S1d). 

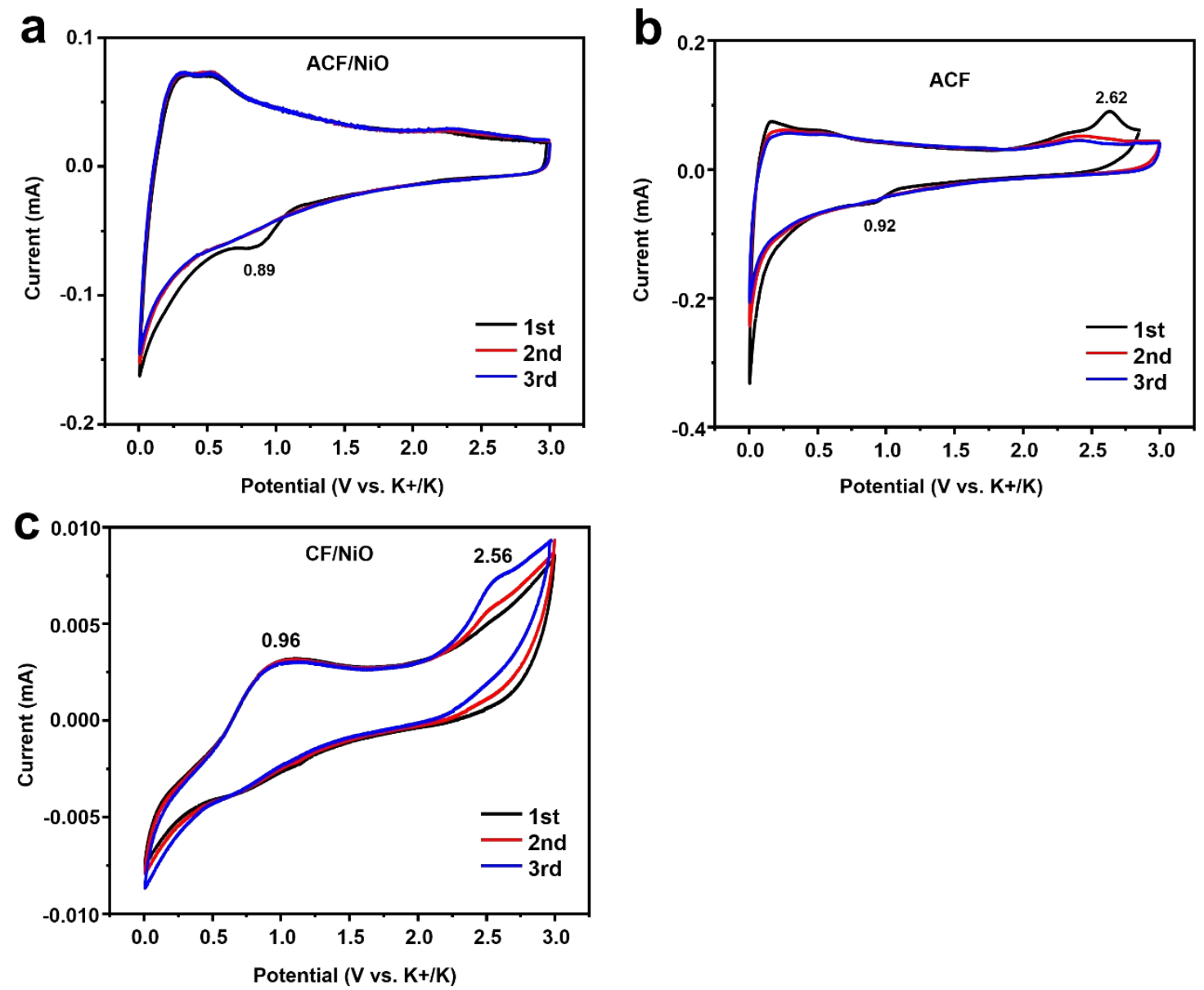

Figure S2. Cyclic voltammograms of (a) ACF/NiO, (b)ACF and (c) CF/NiO anode at $0.1 \mathrm{mV} \mathrm{s}^{-1}$.

In the anode scan, three peaks appeared for the first time at $1.71,2.00$, and $2.38 \mathrm{~V}$, the subsequent scans evolved into a peak of $2.38 \mathrm{~V}$ (Figure 5a). This peak may be related to the reaction of $\mathrm{NiS}$ and potassium-ion, compared to the $\mathrm{CV}$ curves of $\mathrm{CF} / \mathrm{NiO}, \mathrm{ACF}$ and $\mathrm{ACF} / \mathrm{NiO}$ (Figure S2). 

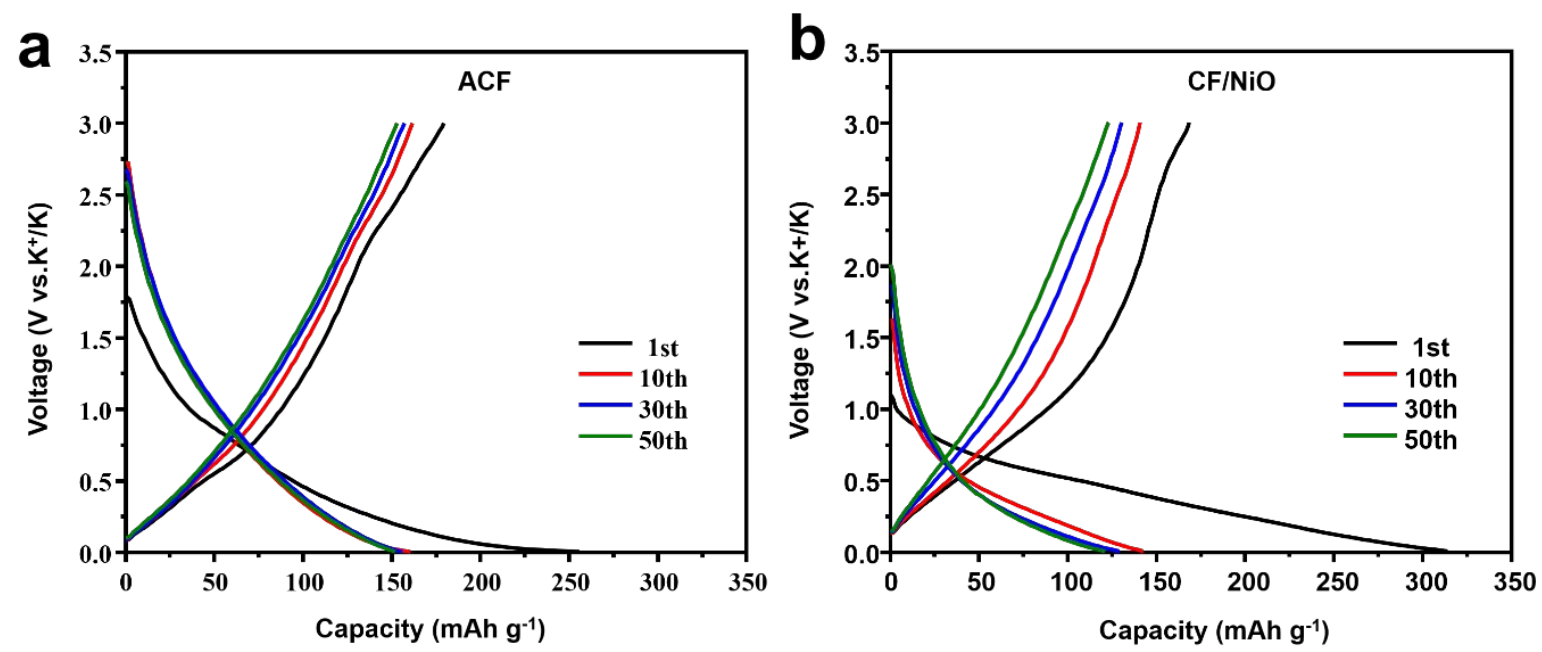

Figure S3. Charge-discharge profiles of (a) $\mathrm{ACF}$ and (b) $\mathrm{CF} / \mathrm{NiO}$ anode at a current density of $0.5 \mathrm{~A}$ $\mathrm{g}^{-1}$.

The discharge-charge curve of $\mathrm{ACF}$ and $\mathrm{CF} / \mathrm{NiO}$ anode where no inconspicuous quasiplateau exists (Figure S3). 
Table S1. XPS analysis results of ACF, $\mathrm{CF} / \mathrm{NiO}, \mathrm{ACF} / \mathrm{NiO}, \mathrm{ACF} / \mathrm{NiS}$.

\begin{tabular}{ccccccccc}
\hline \multirow{2}{*}{ Samples } & \multicolumn{3}{c}{ XPS (wt. \%) } & & \multicolumn{3}{c}{ C1s (\%) } \\
\cline { 2 - 4 } \cline { 7 - 8 } & C & O & $\mathbf{S}$ & & C=C/C-C & C-N/O & COOR \\
\hline ACF/NiS & 91.1 & 5.5 & 2.9 & & 59.95 & 34.64 & 5.40 \\
ACF/NiO & 94.1 & 5.4 & 0.2 & & 49.84 & 41.75 & 8.41 \\
ACF & 92.8 & 7.2 & 0.1 & & 58.16 & 36.87 & 4.97 \\
CF/NiO & 91.6 & 8.4 & 0.1 & & 55.17 & 38.01 & 6.81 \\
\hline
\end{tabular}

The XPS analysis of ACF, $\mathrm{CF} / \mathrm{NiO}, \mathrm{ACF} / \mathrm{NiO}$ and $\mathrm{ACF} / \mathrm{NiS}$ was showed in Table S1. It was noted that the $\mathrm{ACF} / \mathrm{NiS}$ contained higher sulfur content of $2.9 \%$. 
Table S2. EDS analysis results of ACF/NiS.

\begin{tabular}{cc}
\hline Element & Atomic (wt. \%) \\
\hline $\mathrm{C}$ & 79.87 \\
$\mathrm{O}$ & 2.66 \\
$\mathrm{~S}$ & 10.62 \\
$\mathrm{Ni}$ & 5.69 \\
$\mathrm{~N}$ & 1.05 \\
$\mathrm{H}$ & 0.11 \\
\hline
\end{tabular}

The EDS analysis of ACF/NiS was showed in Table S2. The NiS content on the surface of $\mathrm{ACF} / \mathrm{NiS}$ is $5.69 \%$. 